\title{
Assessing the consequences of pipeline accidents to support land-use planning
}

\author{
J. Giovanni Ramírez-Camacho ${ }^{\mathrm{a}}$, Federica Carbone ${ }^{\mathrm{b}}$, Elsa Pastor ${ }^{\mathrm{a}, *}$, Roberto Bubbico ${ }^{\mathrm{b}}$, \\ Joaquim Casal $^{\mathrm{a}}$ \\ ${ }^{a}$ Centre for Technological Risk Studies (CERTEC), Department of Chemical \\ Engineering, Universitat Politècnica de Catalunya - BarcelonaTech (UPC). Diagonal \\ 647, 08028-Barcelona, Catalonia, Spain. \\ ${ }^{b}$ Dipartimento di Ingegneria Chimica, Materiali, Ambiente, Università di Roma "La \\ Sapienza”, 00184 Roma, Italy.
}

\begin{abstract}
With the rapid development of industry, the number of pipelines that are proposed or under construction is increasing year by year, connecting different regions of a country and, more and more, different countries. Thus, an accidental loss of containment from a pipeline involves a certain risk, which could imply potential consequences on people, equipment and environment. Therefore, the existence in some places of a large net of pipelines has a clear influence on land-use planning, especially in the zones with intense activities, which usually are the inhabited zones. In this paper, a historical analysis is performed on a sample of 1063 accidents that occurred in onshore pipelines, to illustrate the risk associated to these systems and its significance in land-use planning.
\end{abstract}

Keywords: Pipelines; Transport; Accidents; Failure causes/consequences; Hazardous materials; Oil/gas.

\section{Introduction}

The characteristics of the present highly complex and interconnected societies require a continuous flow of materials and energy from one geographical area to another. In particular huge amounts of often hazardous materials, mainly liquids or gases, are transported from production/extraction sites, through processing plants, to the final consumption areas.

The transportation can be performed by different modes: road, rail, ship (sea/river) or pipeline. Most of these modes have a strong interaction with the landscape, as often the transport takes place over long distances, crossing both rural and urban areas.

One of the most used modes in the case of fluids is the transport through pipelines, which is usually considered one of the safest among the aforementioned ones, as discussed in Section 2. Nevertheless, most of the transported fluids are flammable or toxic. Thus, an accidental loss of containment from a pipeline involves a certain risk, which could imply potential consequences on people, equipment and environment. These consequences will depend on the amount and properties of the released material, and on the features of the affected zone (rural or urban). Taking into account the large

\footnotetext{
* Corresponding author. Tel.: +34 93 4016675; fax: +34 934017150.

E-mail addresses: elsa.pastor@upc.edu (E. Pastor).
} 
length of pipelines in many countries, with the consequent interaction with the land, and the huge amount of materials transported every day, the occurrence of an accident cannot be neglected. In fact, accidents or incidents following the release from a pipeline have actually occurred with a certain frequency, and some of them with severe consequences.

In some places, the existence of a large net of pipelines has therefore a clear influence on land-use planning, especially in the zones with intense industrial activities, which usually are also the most inhabited ones. Concerning this scenario, two possible situations can be found: a) the existence of a pipeline in a zone initially not inhabited, which becomes urban later on, and $b$ ) the existence of a pipeline in an already existing urban zone. In both cases, the risk inherent to a possible loss of containment increases as compared to that in a rural zone, due to the activities associated to the human presence. However, even in uninhabited regions an accident can have serious consequences on the environment, polluting soil or water or damaging areas of special ecological interest.

These are complex situations. Land-use planning aims to protecting human health and the environment though the definition of safety zones around the pipeline. It contributes also to reducing the risk of third part activities -especially excavation works- by applying different measures; these can include technical measures such as increasing pipe wall thickness or burial depth or marking the pipeline corridor, or organizational ones as, for example, ensuring that any excavation work will be communicated before starting (COWI, 2011).

It is nowadays widely recognized the significance of historical analysis of past accidents as a source of valuable information on their main aspects (types, frequency, causes, etc.). In this paper such a historical survey is performed on a set of 1063 accidents that have occurred in onshore pipelines, with a statistical analysis of their main features.

\section{Worldwide networks for onshore pipelines: a relatively safe alternative}

Pipeline transport of liquids and gases is an important sector of the oil and gas industry and, more generally, process industry. After World War II the construction of pipelines experienced a huge increase, connecting different regions of a country and, more and more, different countries. Among the longest pipelines we can cite the Natural Gas Transmission System in Russia, with diameters up to $1422 \mathrm{~mm}$ and 170.7 thousand kilometers in length (GAZPROM, 2015), and the Trans-Alaska Pipeline System, transporting crude oil, with a diameter of $1219 \mathrm{~mm}$ and a length of $1300 \mathrm{~km}$ (APSC, 2013).

The length of pipelines is continuously increasing. As an example, Fig. 1 shows the variation of the total length of the European gas transmission pipelines system in EGIG (2015); a steady growth can be observed during the last forty-three years. 




Fig. 1. Total length of the European gas transmission system in EGIG (EGIG, 2015).

When transporting a hazardous fluid, pipelines are a relatively safe system as compared to other transportation modes. Although millions of kilometres of pipelines are installed, the frequency of fatal accidents is relatively low (Papadakis, 1999; Buonvicini et al, 2015). Comparing the diverse transportation possibilities, Boot (2013) emphasized the following points:

- Rail/road/ship are batch modes, while pipeline is a continuous one.

- Batch systems imply loading/unloading activities, which involve a significant contribution of human factor. When all major accidents (both in fixed plants and in transportation) are analyzed, it is found that $8-10 \%$ have occurred during loading/unloading (Vílchez et al, 1995).

- In batch transportation, the failure frequency includes the probability of the truck/railcar/ship being present. The pipeline has a $100 \%$ presence factor.

Boot (2013) presented a comparative analysis on the transportation of 100,000 t/year of propane by the different transport modes, based on the associated quantitative risk analysis. The required number of transports for rail, road and ship modes was taken into account, and a diameter of $65 \mathrm{~mm}$ was considered for the pipeline. The results showed that the pipeline mode was more dangerous than the other modes when accidents with reduced consequences were taken into consideration, but it was significantly safer for more severe accidents, being as an average less dangerous than the other modes.

Another comparative study was performed by the Transportation Research Board (TRB, 2004), taking into account the rate of fatalities and injuries per ton-mile. The result showed that pipeline transport was overall the safest system (only tank-ship and barge were safer in terms of injuries per ton-mile).

However, even though these analyses show that pipeline transport is a relatively safe system, it is a fact that, due to the large number of pipelines on many countries, accidents occur with consequences on people and environment. An example of a very severe one is that occurred in Ghislenghien, Belgium in 2004 (ARIA, 2009). An excavation machine damaged a pipeline transporting natural gas; a few weeks later, an 
increase in the pressure caused the explosion of the pipe. A large jet fire appeared immediately and large pipe fragments were ejected. 23 persons were killed and 132 were injured. Another case, with severe consequences on environment, was the one occurred in Marsall (Michigan) in 2010, when a pipeline transporting a heavy crude oil broke and a spill of $4,200 \mathrm{~m}^{3}$ polluted the Kalamazoo River.

It is thus believed that an accurate historical analysis of a sample of accidents as large as possible can give interesting and useful information on their modalities and consequences, allowing to identify appropriate preventive measures.

\section{Accident types}

Following the release of a hazardous material from a pipeline, the accidental sequence can follow diverse paths according to the released material properties (flammability, toxicity and volatility), the pipeline situation (underground or surface), the release characteristics (full bore rupture, a hole, etc.), the meteorological conditions and the environmental circumstances (urban, rural). The event tree in Fig. 2 shows a simplified scheme of the diverse possibilities.

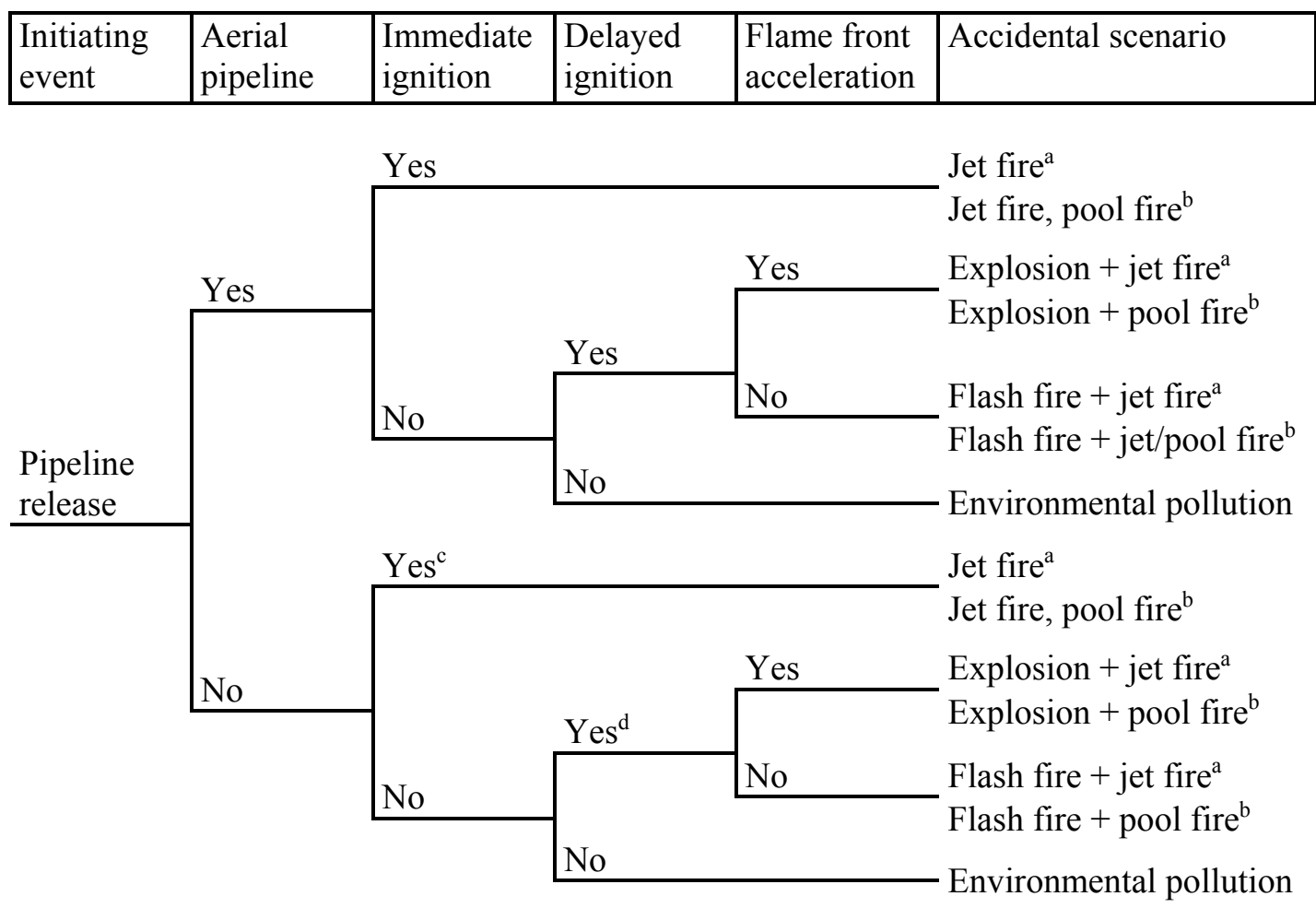

\footnotetext{
a Flammable gases.

${ }^{\mathrm{b}}$ Flammable and volatile liquid materials.

${ }^{\mathrm{c}}$ Only if the jet creates a crater.

${ }^{\mathrm{d}}$ If there is a crater or if gas/vapor flows through the organize into the atmosphere.
}

Fig. 2. Event tree for a release in a pipeline transporting hazardous gases and liquids.

An important aspect is whether the pipe is aerial or buried. If it is aerial and the fluid is flammable, there is the possibility -especially in a zone with human activity- of immediate ignition. In this case there will be a jet fire if the released material is a gas, or 
more probably a pool fire (even though a jet fire could also occur) if it is a liquid. If there is no ignition, the product, if liquid, will pollute the soil and potentially the aquifers -there is also the possibility of being drained towards a torrent or a creek- or it will disperse into the atmosphere if it is a gas or a volatile liquid. If the material is flammable, there is still the possibility of delayed ignition; in this case, there can be a flash fire or a vapor cloud explosion and, afterwards, a pool fire (liquid) or a jet fire (gas).

In buried pipes the situation will change depending on whether the initial release originated a crater. In this case, similar to that of an aerial pipe, there can be an immediate ignition, with a jet fire (gas release) or a pool fire or a jet fire (liquid release); again, if there is late ignition, a flash fire or a vapor cloud explosion can occur, followed by a pool fire (liquid release) or a jet fire (gas). Without any ignition, environmental pollution will occur. If there is no crater, then a liquid will enter the soil and possibly can create a pool above ground, while a gas can flow through the pores of the soil into the atmosphere.

\section{Data collection and filtering methods}

The survey was performed by using accident databases and other Internet sources. Most records were obtained from the Major Hazard Incident Data Service database (MHIDAS, 2007), managed by the UK Health and Safety Executive (HSE); it includes 14,168 records (1431 on pipelines, both offshore and onshore) corresponding to accidents that occurred in 95 countries from the beginning of the $20^{\text {th }}$ century until November 2006. For the study at hand only accidents that happened after January $1^{\text {st }}$ 1980 were considered, as in the last thirty-five years both safety considerations and the management of emergencies have improved, and the requirements for registering such accidents were less rigorous before that date.

In order to identify the records specifically related to accidents originated from longdistance onshore pipelines, a first filtering operation has been conducted on the MHIDAS database. For every incident recorded, the location of occurrence has been encoded with the fields OG (general origin) and OE (specific origin). Between the general origins (storage, transfer, process, etc.) the transport activity has been selected. In this category, the incidents with the specific origin in pipeline transport have been filtered. Later on, by analyzing the "Abstract" field of the incidents -one by one- many records have been removed for a number of reasons: those occurred from off-shore pipelines, those caused by sabotage or from short-distance pipelines, such as transfer pipelines, gas service lines or LNG pipelines, etc. Finally, a collection of 639 records has been obtained.

One of the limitations of this database is the fact that one accident may have more than one record if there is more than one cause, more than one type of event or various materials involved. To solve this problem, a new database (DB1) -with a new structure of the existing fields and new fields- was created in Microsoft Excel format, by which data filtering and post-processing strategies could be applied. After applying this extraction process, the number of selected accidents was considerably reduced. Finally, a collection of 639 accidents was considered. The fields used in this study are shown in Table 1. 
Table 1

Database fields used in this study.

\begin{tabular}{ll}
\hline MHIDAS field & Description \\
\hline AN & MHIDAS accident number \\
DA & Date of accident \\
LO & Location \\
PD & Population density \\
IT & Incident type \\
OG & Origin (general and specific) \\
GC & General cause \\
SC & Specific cause \\
MN & Material name \\
MH & Material hazards \\
QY & Quantity of material involved \\
DR & Damages \\
KR & Number of fatalities \\
IR & Number of injured persons \\
ER & Number of evacuated persons \\
AB & Abstract (short explanation of the accident) \\
\hline Additional fields &
\end{tabular}

Part of the system involved

System type

Installation type

Year of installation

Pipeline diameter

Operating pressure

Pressure at the time of failure

Material recovered

Environmental damages

Sources

During this analysis, the following aspects have been taken into account:

- In MHIDAS, the field "Incident type" classifies the accidents under four basic categories: fire, release, explosion and gas cloud. However, each basic IT may include more detailed

information. To better organize the data, two new fields were added, "General incident" and "Specific incident", replacing the previous one. So the first field classifies each accident according to the above four basic categories, and the second one indicates the specific type of event. For example, a fire can be a jet fire, a pool fire, etc. If the information related to specific events was incomplete or lacking in some records, only the four basic types were applied.

- The field "General incident" indicates the final event/s that occurred, after a loss of containment, and as a result of the possible combinations of basic events. The different combinations may result in:

- Release (liquid release): when a loss of containment of a liquid with low volatility took place, for which a vapor cloud formation has not taken place. This event is typical for substances such as diesel, jet fuel and fuel oil.

- Release followed by vapor cloud dispersion (liquid release): it indicates the release of a compressed gas (natural gas), pressurized liquid gas (LPG, 
ammonia) or volatile liquids (crude oil, gasoline, naphtha and other light petroleum products). In some cases, a liquid pool or liquid migration is also considered. The spillage or release that caused gas clouds was not always reported, nevertheless it is evident that gas/vapor clouds are a direct consequence of an unwanted gas emission or emanation of vapors from volatile liquids (toxic and flammable); therefore, all the gas clouds (gases and volatile liquids) were considered to be preceded by a release.

- Release followed by fire: when a flammable substance, after the action of an ignition source, leads to a fire. It refers to jet fires, flammable gas clouds, or flammable vapor clouds generated by the vaporization of volatile/nonvolatile liquids.

- Release followed by explosion: this event occurs, under the same conditions of the previous one, where a flame front acceleration condition occurs.

- Release followed by explosion and fire: when the explosion leads also to a fire of the substance that continues to be released from the rupture site or that has reached another site by migration.

- By referring to every type of general incident that participates in the events sequence, different types of specific incidents have been defined. In particular, four types of release have been identified:

- Leak: it refers to the release of either a gas or a liquid;

- Spill: it refers, mainly, to a sudden liquid release from a hole;

- Full bore rupture: it refers to the mechanism of rupture, where a crack or a "full ball rupture" damages a part of pipe greater than its diameter. This type of release leads, in most of the cases, to the automatic shut-down of the line;

- Physical explosion: it has been defined as a particular case of catastrophic rupture, depending on the length of the section involved, of a compressed gas pipeline or pressurized liquid pipeline.

- In some cases, the type of initial event that caused the incident was unknown. Whilst a release was generally the cause of a fire or an explosion, such an event was usually cited only if it was of long-lasting and/or if it caused serious damage. Therefore, in cases where the type of initial release could not be determined, these were simply classified as "unknown release".

- The spillage or release that caused gas clouds was not always reported, nevertheless it is evident that gas/vapor clouds are a direct consequence of an unwanted gas emission or emanation of vapors from volatile liquids (toxic and flammable); therefore, all the gas clouds (gases and volatile liquids) were considered to be preceded by a release.

The quality of the information of the records extracted from MHIDAS brought some challenges in its analysis, since the information was incomplete in many of them (i.e. the description was rather vague or short and details on the event sequence were lacking). This limitation has also been claimed by other authors in related studies (Hauer \& Hakkert, 1988; Hemmatian et al., 2014). Another drawback is that this database was decided to be no longer updated, so it only provides information on accidents up to 2006. 
In order to achieve an information as accurate, updated and complete as possible, a detailed Internet search for specific data on most of the accidents was conducted. This search was carried out by consulting freely accessible information such as other data bases, accident reports and technical reports. At the same time, an expansion of the space-time search intervals up to 2014 was performed. The main sources of information were:

- The Analysis, Research and Information on Accidents database (ARIA, 2012)

- The European Oil Company Organization for Environment, Health and Safety (CONCAWE, 2013)

- The Transportation Safety Board of Canada (TSB, 2014)

- The U.K. Health and Safety Executive (HSE, 2014)

- The U.S. Department of Transportation, Pipeline and Hazardous Materials Safety Administration (DOT-PHMSA, 2014)

- The U.S. National Transportation Safety Board (NTSB, 2014).

After this parallel research, the data collected were transformed into a second database (DB2) in accordance with the model and format of the database DB1. DB2 included a total of 542 additional accidents.

When different accident databases and other resources are used the volume of information increases significantly. Consequently, the search and retrieval of data becomes difficult and, in some cases, information can be duplicated. To avoid this situation, a matching procedure between both databases (DB1 and DB2) was performed, following a similar approach used by other authors to integrate data from several sources (Trépanier et al., 2007, 2009). This procedure was done manually, focusing on the "Date of incident" and "Location" fields as initial references to find matching records. Once the overlap between matched records had been assured, data were integrated in a common master record. After applying this procedure, a collection of 1063 accidents was finally obtained. Those records were statistically analyzed in order to find common features among different sets of accidents.

\section{Results}

\subsection{Types of events}

\section{General events}

Most of the events (97\%) occurred in pipes, and only a few ones in pump or compression stations. The different types of accidents were classified as follows: release, fire, explosion and gas cloud. In all 1063 entries in the database, the information related to general event was known. Their contribution can be seen in Table 2. An initial release was assumed in all cases. Because more than one accidental phenomena can exist in the same accident, the sum of all percentages is more than $100 \%$. Since an initial release was assumed in all cases, for the three remaining events, gas cloud was the most frequent; this event refers both to gases (flammable, corrosive and/or toxic) and volatile liquids (flammable). The second most frequent event was fire, followed by explosion. Practically in two out of three events there was a gas cloud that eventually 
dispersed, and in about one out of four there was a fire, while in one out of ten events there was an explosion.

Table 2

Ranking of accidental sequences.

\begin{tabular}{llc}
\hline General event & Number of entries & \% of total \\
\hline Release & 1063 & 100.0 \\
Gas cloud & 643 & 60.5 \\
Fire & 256 & 24.1 \\
Explosion & 131 & 12.3 \\
\hline \multicolumn{2}{l}{ Classification with exclusive categories } \\
\hline Release $\rightarrow$ Gas cloud dispersion & 643 & 60.5 \\
(gases and volatile liquids) & & \\
Release $\rightarrow$ Fire & 185 & 17.4 \\
Release (liquids of low volatility) & 104 & 9.8 \\
Release $\rightarrow$ Explosion $\rightarrow$ Fire & 71 & 6.7 \\
Release $\rightarrow$ Explosion & 60 & 5.6 \\
\hline
\end{tabular}

Using a classification with exclusive categories, i.e. a distribution in which the sum of the percentages is 100 , the highest contribution is that corresponding to accidents in which a release and a gas cloud have occurred (60.5\%). To a lesser extent, the second most frequent sequence was a release followed by fire, with $17.4 \%$. Release alone had a contribution of $9.8 \%$, and refers to release of low volatile liquids (e.g. diesel), in which the risk of cloud formation is reduced. Release followed by explosion occurred in $12.3 \%$ of cases (in $6.7 \%$ the explosion was followed by a fire). Practically in two out of three events there was a gas cloud that eventually safely dispersed, and in about one out of four there was a fire, while in one out of ten events there was an explosion.

Specific events

The specific events involved in the accidents have been analyzed (Table 3 ). Concerning the type of release, the greatest contribution was due to leaks ( $40.5 \%$ of total), followed by full bore rupture (27.5\%) and spill (24.5\%). Physical explosion of the pipe occurred with a much lower frequency ( $4.8 \%$ of the total).

Table 3

Distribution by specific events.

\begin{tabular}{|c|c|c|c|}
\hline Specific event & Number of entries & $\%$ of category & $\%$ of total \\
\hline \multicolumn{4}{|c|}{ Accidents with at least one of the following types of release } \\
\hline Leak & 431 & 40.5 & 40.5 \\
\hline Full bore rupture & 292 & 27.5 & 27.5 \\
\hline Spill & 260 & 24.5 & 24.5 \\
\hline Physical explosion & 51 & 4.8 & 4.8 \\
\hline Unknown type of release & 29 & 2.7 & 2.7 \\
\hline \multicolumn{4}{|c|}{ Accidents with at least one of the following types of gas cloud } \\
\hline Flammable gas cloud & 635 & 98.8 & 59.7 \\
\hline
\end{tabular}


Toxic/Flammable gas cloud 8

\begin{tabular}{|c|c|c|c|}
\hline \multicolumn{4}{|c|}{ Accidents with at least one of the following types of fire } \\
\hline Jet fire & 139 & 54.3 & 13.1 \\
\hline Flash fire & 55 & 21.5 & 5.2 \\
\hline Pool fire & 39 & 15.2 & 3.7 \\
\hline Fireball & 32 & 12.5 & 3.0 \\
\hline Unknown type of fire & 49 & $19.1^{\mathrm{a}}$ & $4.6^{\mathrm{b}}$ \\
\hline \multicolumn{4}{|c|}{ Accidents with at least one of the following types of explosion } \\
\hline Vapor cloud explosion & 131 & 100.0 & 12.3 \\
\hline
\end{tabular}

For the events involving gas cloud dispersion, flammable clouds had a very high frequency ( $98.8 \%$ of the category), which is in good agreement with the fact that most of the high-risk materials in accidents are heavier than air (gasoline, LPG, etc.). Toxic/flammable clouds existed only in $0.8 \%$ of the total, and are related to materials such as ammonia and CO.

With regard to the events classified as involving fire, the most frequent one was jet fire ( $54.3 \%$ of the category, $13.1 \%$ of the total), usually found in the release of a pressurized fluid through a hole. It was followed by flash fire (5.2\% of the total). However, it should be mentioned the fact that a vapor cloud explosion always involves a flash fire as well, even though in such case the databases usually mention only the explosion as a major accident (following the criterion usually applied in risk analysis).

\subsection{Accidents distribution according to their cause}

Distribution by general cause

With regard to the general causes of the accidents, the possibilities under consideration were the following: third party activity, corrosion, mechanical failure, operational/human error, natural hazards and equipment failure. Of the 1063 accidents taken into account in this survey, the general cause was known only in 759.

The contribution of the various general causes has been summarized in Table 4. Three of them show a substantial contribution: third party activity (37.7\% of known cases), corrosion (20.9\%) and mechanical failure (19.5\%); operational/human error, natural hazards and equipment failure have a lower contribution.

\section{Table 4}

General causes of the accidents.

\begin{tabular}{lll}
\hline General Cause & Number of entries & \% of total \\
\hline Known general cause & 759 & 71.4 \\
Unknown general cause & 304 & 28.6 \\
\cline { 2 - 3 } & Number of entries & $\%$ of known cause* \\
\cline { 2 - 2 } Third party activity & 286 & 37.7
\end{tabular}




$\begin{array}{lll}\text { Corrosion } & 159 & 20.9 \\ \text { Mechanical failure } & 148 & 19.5 \\ \text { Operational/human error } & 64 & 8.4 \\ \text { Natural hazards } & 53 & 7.0 \\ \text { Equipment failure } & 52 & 6.9\end{array}$

* Percentages do not total $100 \%$ because 3 entries involved more than one general cause.

Accidents can be classified as having a single cause or more than one cause. In 756 records there was only one single cause. Of these, third party activity was the most frequent one, followed by corrosion and mechanical failure. More than one cause were found only in three accidents. Mechanical failure was present in all these three cases associated with other causes, being those of corrosion and third part activity.

\section{Distribution by specific cause}

The distribution according to the specific cause can be seen in Table 5. The most frequent cause of the accidents was third party activities. Most of these events (76\%) were caused by excavation machinery, followed by damages by a vehicle or other equipment not related to excavation activity. Following, with much lower frequencies are shipping traffic in river and heavy loads (for example, from a truck). In $6.3 \%$ of the cases there was no information available on the type of third party activity.

\section{Table 5}

Specific causes of the accidents.

\begin{tabular}{lrcc}
\hline Specific Cause & Number of entries & \% of general cause & \% of known cause \\
\hline Third party activity & & & \\
\hline Excavation machinery & 218 & 76.2 & 28.7 \\
Vehicle/other equipment & 44 & 15.4 & 5.8 \\
not related to excavation & & & \\
activity & & 1.0 & 0.4 \\
Shipping traffic in river & 3 & 0.7 & 0.3 \\
Heavy loads & 2 & 0.3 & 0.1 \\
High-voltage electrical & 1 & 6.3 & 2.4 \\
Unknown & 18 & & \\
\hline Corrosion & & 47.8 & 40.0 \\
\hline External corrosion & 76 & 22.6 & 2.1 \\
Internal corrosion & 36 & 10.1 & 4.1 \\
Stress corrosion cracking & 16 & 19.5 & $*$ \\
Unknown & 31 & & 5.7 \\
\hline Mechanical failure & & 29.1 & 3.3 \\
\hline Weld failure & 43 & 16.9 & 2.9 \\
Material defects & 25 & 14.9 & 2.1 \\
Overpressure & 22 & 10.8 & 1.8 \\
Construction defects & 16 & 9.5 & 0.1 \\
Aging & 14 & 0.7 & \\
Supports failure & 1 & & \\
& & &
\end{tabular}




\begin{tabular}{|c|c|c|c|}
\hline Specific Cause & Number of entries & $\%$ of general cause & $\%$ of known cause \\
\hline Unknown & 29 & 19.6 & 3.8 \\
\hline \multicolumn{4}{|c|}{ Operational/human error } \\
\hline Maintenance & 23 & 35.9 & 3.0 \\
\hline Repair/replacement & 20 & 31.3 & 2.6 \\
\hline Startup & 5 & 7.8 & 0.7 \\
\hline General operations & 4 & 6.3 & 0.5 \\
\hline Decommission & 3 & 4.7 & 0.4 \\
\hline Valve operations & 3 & 4.7 & 0.4 \\
\hline Hot tapping & 1 & 1.6 & 0.1 \\
\hline Pigging operations & 1 & 1.6 & 0.1 \\
\hline Pressure testing & 1 & 1.6 & 0.1 \\
\hline Shutdown & 1 & 1.6 & 0.1 \\
\hline Unknown & 2 & 3.1 & 0.3 \\
\hline Natural hazards & & & * \\
\hline Land slides & 26 & 49.1 & 3.4 \\
\hline Floods & 12 & 22.6 & 1.6 \\
\hline Lightning & 5 & 9.4 & 0.7 \\
\hline Heavy rains & 5 & 9.4 & 0.7 \\
\hline Cold weather & 2 & 3.8 & 0.3 \\
\hline Erosion & 1 & 1.9 & 0.1 \\
\hline Unknown & 4 & 7.5 & 0.5 \\
\hline \multicolumn{4}{|l|}{ Equipment failure } \\
\hline Flange & 18 & 34.6 & 2.4 \\
\hline Valves & 13 & 25.0 & 1.7 \\
\hline Pumps/compressor & 6 & 11.5 & 0.8 \\
\hline Other & 7 & 13.3 & 0.9 \\
\hline Unknown & 8 & 15.4 & 1.1 \\
\hline
\end{tabular}

With respect to the accidents caused by corrosion, the most frequent type was external corrosion, followed by internal, and lastly, stress corrosion cracking. These data indicate that maintenance is a very important issue to keep a pipeline in a safe condition.

Concerning the accidents with "mechanical failure", the most frequent specific cause was weld failure (43 cases), followed by materials defects, overpressure, construction defects and aging; here again the importance of maintenance is clear.

Natech accidents have also a certain contribution. Among the accidents originated by natural hazards, the most frequent specific cause was landslides (26 cases), followed, in a lesser proportion, by floods (12 cases) and lighting and heavy rains with the same contribution. These natural hazards occur often in abrupt landscapes, with steep land and torrents, and are not easy to avoid.

With regard to the events caused by operational/human error, the most frequent source of errors were maintenance activities and repair/replacement operations. To a lesser extent are startup and general operations. Though this group is much smaller than, for 
example, third party activities, it is important to be highlighted because this contribution can be significantly reduced with appropriate training of operators.

Finally, for events caused by equipment failure, the most important contribution was that of flange failures, followed by valves failures and pumps/compressors malfunctioning, which raises evidence of the most interesting parts of the system to be inspected.

A special case is that of domino effect when two or more pipes are installed in the same hallway: a jet released from one of the pipes can seriously damage another one by abrasion (underground pipes) or thermal action (jet fire) (Ramirez-Camacho et al., 2015).

\subsection{Materials involved}

Table 6 summarizes the information concerning the materials involved in the event. As one accident can involve more than one material, the sum of the percentages is again greater than 100. 14 entries involved had more than one material, of which nine cases involved two materials each, four cases involved three materials each, and only one case involved four materials.

\section{Table 6}

Main materials involved in accidents in pipelines.

\begin{tabular}{lrl}
\hline Material & Frequency & \% of total \\
\hline Gasoline & 304 & 28.6 \\
Natural gas & 289 & 27.2 \\
Crude oil & 288 & 27.1 \\
Diesel & 52 & 4.9 \\
Jet fuel & 52 & 4.9 \\
LPG & 34 & 3.2 \\
Kerosene & 15 & 1.4 \\
Petroleum products & 11 & 1.0 \\
Fuel oil & 10 & 0.9 \\
Anhydrous ammonia & 7 & 0.7 \\
Naphtha & 7 & 0.7 \\
Others & 14 & 1.3 \\
\hline
\end{tabular}

* Percentages do not total $100 \%$ because 14 events involved more than one material.

Gasoline, natural gas and crude oil were the materials most frequently found, with a large difference with respect to the others. Ammonia appeared only in 7 cases.

Nevertheless, these values should be compared with the length of pipeline transporting these products (an information rather difficult to gather), in order to get a better idea of their relative frequency per unit length.

If the type or condition of the material is analyzed (Table 7), it is clear that liquids were the most frequently involved materials (about $74 \%$ of events); this is in good agreement with the fact that most of the materials transported by pipelines are liquids. 
Table 7

Accidents classified as a function of the materials involved.

\begin{tabular}{lll}
\hline Condition & Number of entries & \% of total* \\
\hline Liquid & 784 & 73.8 \\
Gas & 299 & 28.1 \\
\hline
\end{tabular}

* Percentages do not total $100 \%$ because 14 events involved more than one material.

In Table 8, the results for the type of hazard associated with the released materials (toxic, flammable, corrosive) are summarized. Because some cases involved more than one material, more than one of the hazards considered may exist; for example, 'flammable' and 'toxic' simultaneously. Therefore, the sum of all the hazards is higher than the number of entries. Flammable materials were involved in most of the cases, while toxic and corrosive chemicals show a very small contribution.

\section{Table 8}

Hazards associated with the materials.

\begin{tabular}{lcc}
\hline Hazard & Number of entries & \% of total \\
\hline Flammable & 1081 & 101.7 \\
Toxic & 9 & 0.8 \\
Corrosive & 7 & 0.7 \\
No hazard & 1 & 0.1 \\
\hline
\end{tabular}

\subsection{Environmental pollution according to the released volume}

By referring to the main substances involved, it is interesting to evaluate the number of entries for which environmental pollution has been reported as a function of the volume released. Only $29 \%$ of the total cases (310 entries) reported both the affected system and the quantity of material involved. In Table 9, the distribution of the accidents is illustrated according to the quantity of volume released and the specific type of contamination. Four types of pollution are discussed: soil pollution, water pollution, soil and water pollution, and "other types". The greatest number of accidents led to soil pollution: the most frequent events, according to the volume released, fall in the ranges $5-50 \mathrm{~m}^{3}$ and $100-500 \mathrm{~m}^{3}$. For soil and water pollution, the most frequent cases fall in the ranges $100-500 \mathrm{~m}^{3}$ and $500-5000 \mathrm{~m}^{3}$. Differently, for water pollution, no characteristic distribution has been observed.

Table 9

Distribution of entries by specific contamination according the released volume.

\begin{tabular}{lcccl}
\hline Released Volume & Soil and water & Soil & Water & Other \\
\hline$<5 \mathrm{~m}^{3}$ & 7 & 29 & 5 & 1 \\
$\geq 5$ and $<50 \mathrm{~m}^{3}$ & 8 & 72 & 9 & 1 \\
$\geq 50$ and $<100 \mathrm{~m}^{3}$ & 7 & 31 & 2 & 0 \\
$\geq 100$ and $<500 \mathrm{~m}^{3}$ & 22 & 62 & 12 & 0 \\
\hline
\end{tabular}




\begin{tabular}{lrrrl}
\hline$\geq 500$ and $<5000 \mathrm{~m}^{3}$ & 12 & 17 & 9 & 0 \\
$>5000 \mathrm{~m}^{3}$ & 0 & 4 & 0 & 0 \\
\hline Total of known & 56 & 215 & 37 & 2 \\
\hline
\end{tabular}

\subsection{Population density}

A very important aspect, concerning the consequences on the population, is whether the accident took place in an inhabited zone. Two categories were applied: urban (town or village) and rural (scattered or no population) areas. The corresponding information was known in 566 cases (Table 10). Of these, $68.6 \%$ of the accidents occurred in rural areas, and only $31.4 \%$ occurred in urban zones. However, these percentages should be treated with caution, as the reliability of the data may not be very good: an accident occurred in an urban area is much more evident than a similar one in a rural zone and, therefore, the probability of being included in a database is higher in the first rather than in the second case (Vílchez et al., 1995).

\section{Table 10}

Distribution by population density.

\begin{tabular}{lll}
\hline Population density & Number of entries & \% of total \\
\hline Rural & 388 & 68.6 \\
Urban & 178 & 31.4 \\
\hline
\end{tabular}

\subsection{Consequences on people}

Human life can be impacted by a major accident in several different ways, depending on the severity of the effect and the localization of the population. After a major accident people may die, be injured or have to be evacuated from their homes. Thus, the consequences on people can be classified into three categories: number of deaths, number of people injured, and number of people evacuated. Of the overall number of entries in the database, 667 contained information on the possible occurrence of deaths and of people injured; in the rest of the entries (396), these two values were unknown. In $76.3 \%$ of these 667 entries, no deaths or injuries occurred, while deaths occurred and/or people were injured in the remaining $23.7 \%$.

With regard to the number of deaths, Fig. 3 shows the distribution of the number of entries, according to arbitrary categories (0 dead, 1-10 dead, etc.). The values in brackets indicate the percentage of entries for which this information is known. In 571 cases $(85.6 \%$ of known, $53.7 \%$ of the total) there were no deaths recorded; amongst those in which there were dead people, most of them correspond to the category of 1-10 deaths ( 77 entries, $11.5 \%$ of known, $7.2 \%$ of the total). In very few cases, there were more than 10 deaths recorded (19 entries, $2.8 \%$ of known, $1.8 \%$ of the total), i.e., the percentage of entries with a 'large' number of deaths is low. In total, people were killed in $14.2 \%$ of the entries where details were recorded ( $9.0 \%$ of all the entries).

The maximum number of fatalities was about 600, in an accident occurred in an uninhabited zone near Ufa, Russia (USSR at that time) in 1989. A leak in a pipeline transporting natural gas generated a large flammable cloud and the arrival of two trains originated the explosion; this is in fact a quite anomalous case, as very severe 
consequences on people (trains passengers) occurred even though it was an uninhabited zone.

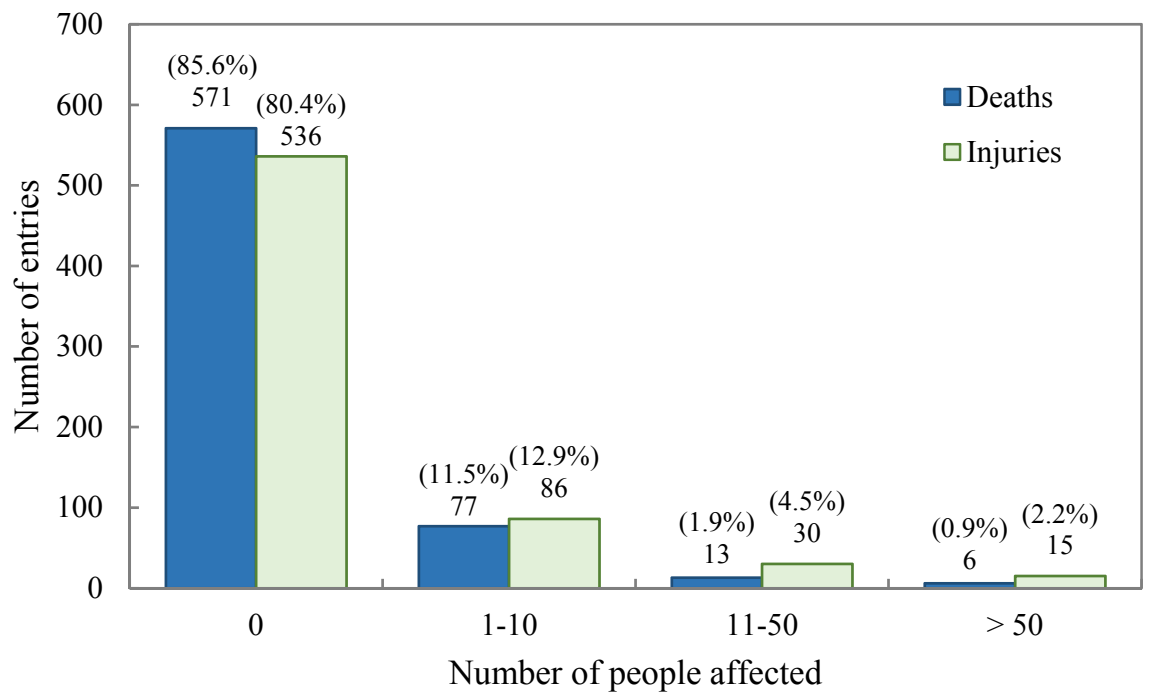

Fig. 3. Events according to the number of deaths and injured people (total known: 667 entries).

The number of people injured has been presented in Fig. 3. In 536 cases $(80.4 \%$ of known, $50.4 \%$ of the total) there were no people injured, while, for the most of entries with details of injured people, the number of injured ranged between 1 and 10 (86 cases) and in 30 cases the number of people injured ranged between 11 and 50. In fewer cases (15) the number of injured was higher than 50. In total, people were injured in $19.6 \%$ of the entries where details were given (12.3\% of all the entries).

The maximum number of people injured, 1800, occurred in 1992 in Guadalajara, Mexico, where a large leak of gasoline caused by corrosion, triggered a series of explosions on the sewer system, destroying 15 kilometers of streets.

425 entries give information on the number of people evacuated as a consequence of the events. Of these, nobody was evacuated in $80.5 \%$ of the cases; amongst those in which there were evacuees, most of them correspond to the category of 1-100 (49 entries, $11.5 \%$ of known, $4.6 \%$ of the total) (Fig. 4). In 21 cases, the number of people evacuated ranged between 101-1000 and in 10 cases the number of displaced people ranged between 1001-10,000. The highest value, approximately 30,000, corresponds to an accident that occurred in 1981 in San Francisco, California (NTSB, 1982), when workers accidentally drilled a pipeline, originating a natural gas cloud. 


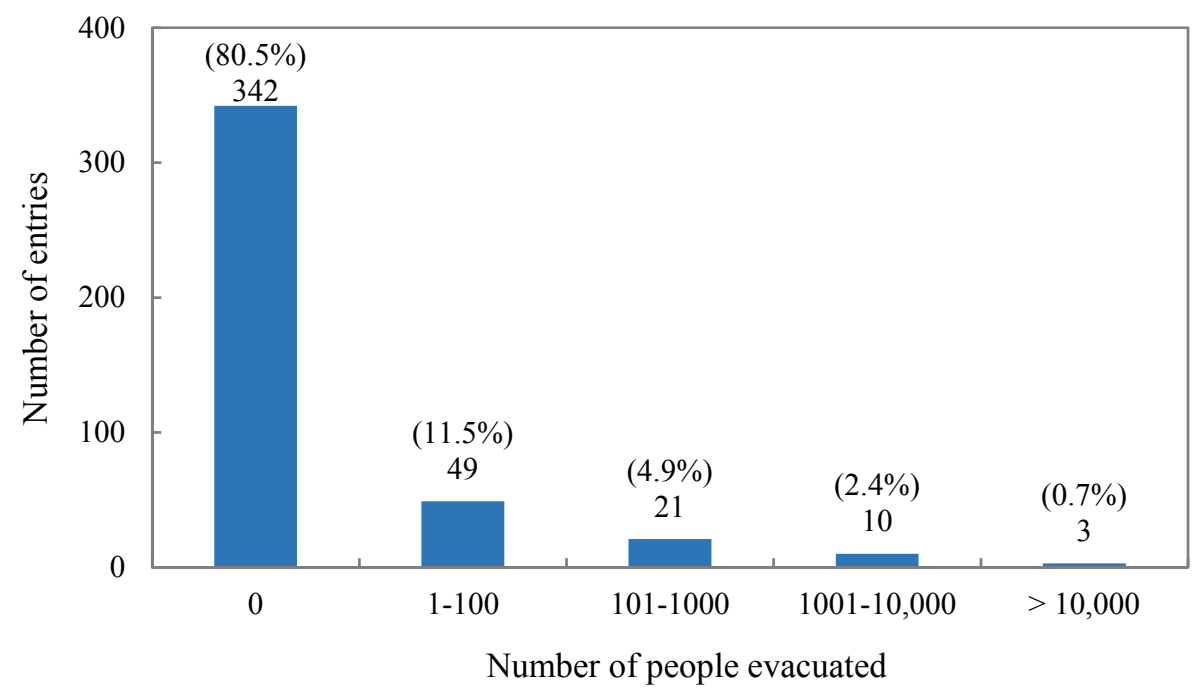

Fig. 4. Events according to the number of people evacuated (total known: 425 entries).

\subsection{Economic losses}

As stated before, people may die, be injured, or be evacuated from their homes due to a major accident; and that situation can make a cost for the company or the administration responsible for the event. Monetization of any aspect of human life is a delicate and polemical subject, although necessary in order to estimate the economic impact of an accident; it is quite difficult to estimate the value of the life of one person, or the possible everlasting costs that a major accident will have on a person that has suffered its effects. However, in practice often it is necessary to assign an economical value to at least some of the possible consequences of major accidents on human life. Guidi et al. (2001) present a list of average values of the costs, per person, calculated for fatalities and injuries.

Of course, other losses can occur also in the accidents: cost of the equipment, buildings, etc. destroyed, cost of remediation actions (soil, groundwater), and indirect costs associated to the interruption of production and loss of company image.

The economic losses incurred as a result of the accidents are only known in 311 cases (29.3\%) of our databases, although no details on the diverse possible contributions are usually given; the data are shown in Table 11 . Most of these events $(70.1 \%)$ had economic losses between more than \$5,000 and \$500,000 US Dollars, and in 19\% of the cases the economic losses ranged between more than $\$ 500,000$ and $\$ 50$ million. In very few cases the economic losses were greater than $\$ 50$ million. The highest value existing in the database, around US\$ 767 million, correspond to the accident occurred in a wetland in Marshall, Michigan (NTSB, 2012).

Table 11

Economic losses derived from events.

\begin{tabular}{lcc}
\hline Economic losses & Number of entries & $\%$ of total \\
\hline$\leq \$ 5,000$ & 30 & 9.6 \\
$>\$ 5,000$ and $\leq \$ 50,000$ & 105 & 33.8
\end{tabular}




\begin{tabular}{lrr}
$>\$ 50,000$ and $\leq \$ 500,000$ & 113 & 36.3 \\
$>\$ 500,000$ and $\leq \$ 5 \mathrm{M}$ & 43 & 13.8 \\
$>\$ 5 \mathrm{M}$ and $\leq \$ 50 \mathrm{M}$ & 16 & 5.1 \\
$>\$ 50 \mathrm{M}$ & 4 & 1.3 \\
\hline
\end{tabular}

These figures clearly show that the economic losses caused by an accident in pipelines can be considerable. However, the information examined does not allow a statistical treatment, as there is an inherent difficulty in the comparison of economic data corresponding to different periods (inflation) and locations. Some values of the 311 cases available were provided directly by MHIDAS, that does not specify whether the economic losses for each record are updated or not to a given reference year; the other values were collected from different data sources (CONCAWE, Aria Database, NTSB, U.S. DOT, NWF, and PHMSA).

\section{Discussion}

Land use includes essentially residential, commercial, industrial and agricultural activities. All these uses imply a series of activities which, if developed near a pipeline, can, under certain circumstances, cause damage to the pipe -a hole or its full rupturewith the consequent loss of containment. As often pipelines transport hazardous fluids, most of them flammable and some toxic, this loss of containment can originate a fire or an explosion.

Even though pipelines can be considered a safe transportation mode as compared to road, rail or ship transportation, it is a fact that accidents occur with a certain frequency. The main reason for this is the extraordinary length of pipelines which are in service nowadays in many countries, a length which is continuously increasing. However, another important reason is the aforementioned existence of certain activities which can interact with pipelines and damage them.

The historical analysis, which results can be considered significant and representative taking into account the large number of cases surveyed, has evidenced this influence: even though accidents occur in uninhabited zones due to corrosion or natural events such as, for example, landslides, among the cases studied the most frequent cause of accidents has been third party activities, especially those associated to excavation machinery.

However, it is a fact that the vicinity of pipelines with the typical activities of an inhabited zone is practically unavoidable: pipelines transport materials to the zones where they must be consumed and these are the urban zones.

Therefore, it is clear that the required regulations must be applied to control the risk that this vicinity implies, decreasing both the expected frequency of the potential accidents as well as their potential effects and consequences. And here clearly land-use planning must play an essential role.

These regulations should, first of all, keep safe distance between the pipelines and inhabited zones; this is especially important when putting in place new pipelines, but also to control the growth of urban zones near an existing pipeline. They must affect 
diverse stakeholders: both the owner and user of the pipeline hallway, and also the users of the land adjacent to the pipe. This land can be used, but under certain control to ensure the prevention of any possible damage as well as the emergency response requirements.

The survey has shown that in almost all $(98.5 \%)$ the accidents analyzed, the material involved was a flammable one; consequently, the associated dangerous phenomena were a flammable gas cloud or a fire, which effects can have an important reach.

Thus, a certain "control distance" should be established, over which any proposed development should be submitted to a risk analysis. No vulnerable elements should be allowed inside the zone covered by a given value of individual risk; this implies a minimum distance, depending on the material transported, the pipeline size, the operating pressure, the distance between blocking valves, etc., for these elements.

Besides the aggressive impacts aforementioned, another important aspect is the maintenance of the pipeline: the survey has shown that $40 \%$ of all accidents were originated by corrosion or mechanical failure; here, pipe aging is a quite important factor. This is not anymore related to the activities close to the pipe, but to its condition; i. e., it is clearly the responsibility of the user/owner of the pipeline. Special mention should be done to the installation of pipelines in zones prone to have landslides, floods, etc.

Even if some accidents will still keep occurring, due to the special features of this transportation mode (increasing length of pipelines, heterogeneity of the land they cross), it is obvious that improving the regulations on adjacent land use, on risk analysis and on maintenance will lead to higher levels of safety.

\section{Conclusions}

Pipelines have a certain major hazard potential, and loss of containment events and accidents still occur whose consequences can be quite significant.

Among the major accidents analyzed, fires are the most common events (jet fires being the most frequent fire type), followed by explosions. This is due to the fact that most of the transported fluids are flammable; the highest contributions are those from gasoline, natural gas and oil, which were involved in $83 \%$ of all accidents.

Pipelines cross both rural and urban zones. Although in inhabited zones there are much more activities which could affect pipelines integrity and interfere with possible releases, it is in rural zones that most of the accidents have occurred $(68.6 \%)$. This is because of the much longer proportion of pipelines running through these zones with respect to those crossing urban ones.

Nevertheless, this analysis shows that an effort should be made in order to improve the safety in inhabited/urban zones, where severe consequences on people can occur. The most frequent cause originating the accidents has been found to be third party activities, essentially excavation machinery. Pipelines often cross other utility service lines (e.g., water, gas service lines, phone lines, etc.), and the potential damage, by third parties 
unaware of the presence of the line, increases; furthermore, activities related to the construction of buildings or new infrastructures near the pipeline can have also a significant contribution. Especially in the case of underground pipes, the hallways should be indicated and protected and, in the event of urban development works, ad-hoc measures should be applied and the regulations concerning both these activities and the protection of pipelines should be strictly applied.

The environmental pollution is directly related to the volume released, which strongly depends on the distance between the blocking valves and on the time needed to stop the release from the section damaged.

Though a significant number of accidents have led to a number of fatalities and injuries to people, the transport of hazardous materials by pipelines seems to be a safer mode than road or rail transport. Nevertheless, an effort should be made to decrease their risk and, in this sense, land-use planning is an essential issue.

\section{Acknowledgements}

J.G. Ramírez-Camacho would like to thank the Mexican National Council of Science and Technology (CONACyT) for the scholarship granted to pursue PhD studies. The authors thank also the Spanish Ministry of Economy and Competitiveness (project no. CTM2014-57448-R) and the Autonomous Government of Catalonia (project no. 2014SGR-413).

\section{References}

APSC, Alyeska Pipeline Service Company, 2013. Trans-Alaska Pipeline System FACTS: A collection of facts compiled over the duration of the operation of the Trans Alaska Pipeline System, by Alyeska Pipeline Service Company. www.alyeska-pipe.com (Accessed: December 16, 2015).

ARIA, Analysis, Research and Information on Accidents, 2009. Rupture and ignition of a gas pipeline, 30 July 2004, Ghislenghien, Belgium. Report No. 27681.

ARIA, Analysis, Research and Information on Accidents, 2014. French Ministry of Ecology, sustainable development and energy. www.aria.developpementdurable.gouv.fr (Accessed: October 15, 2014).

Boot, H., 2013. The use of risk criteria in comparing transportation alternatives, Chemical Engineering Transactions, 31, 199-204.

Buonvicini, S., Antonioni, G., Morra, P., Cozzani, V., 2015. Quantitative assessment of environmental risk due to accidental spills from onshore pipelines. Process Safe Environ, 93, 31-49.

CONCAWE, European Oil Company Organization for Environment, Health and Safety, 2013. Performance of European cross-country oil pipelines. Statistical summary of reported spillages. www.concawe.eu (Accessed: September 24, 2014). 
COWI, 2010. Assessing the case for EU legislation on the safety of pipelines and the possible impacts of such an initiative, Final Report ENV.G.1/FRA/2006/0073. Lyngby, Denmark.

CSA, Canadian Standards Association, 2004. Land use planning for pipelines: a guideline for local authorities, developers and pipeline operators. CSA Special Publication, Ontario, Canada.

DOT-PHMSA, U.S. Department of Transportation Pipeline and Hazardous Materials Safety Administration, 2014. Pipeline Failure Investigation Reports. www.phmsa.dot.gov/ (Accessed: September 22, 2014).

EGIG, European Gas pipeline Incident Data Group, 2015. Gas pipeline incidents, 9th Report of the European Gas pipeline Incident Data group (period 1970 - 2013). Doc. Number EGIG 14.R.0403.

GAZPROM, 2015. Unified Gas Supply System of Russia. www.gazprom.com/ (Accessed: December 16, 2015).

Guidi, G., Ludovisi, G., Mazzarotta, B., 2001. Methodological Approach for the Evaluation, in Economic terms, of the Risk from Industrial Plants Subject to Council Directive 96/82/EC (Seveso II). In: ESREL International Conference, 16-20 September, Torino, Italy.

Hauer, E., \& Hakkert, A. S., 1988. Extent and some implications of incomplete accident reporting. Transp. Res. Rec., 1185, 1-10.

Hemmatian, B., Abdolhamidzadeh, B., Darbra, R.M., Casal, J., 2014. The significance of domino effect in chemical accidents. J. Loss Prev Process Ind., 29, 30-38.

HSE, U.K. Health and Safety Executive, 2014. Contract Research Reports. www.hse.gov.uk/ (Accessed: October 31, 2014).

MHIDAS, Major Hazardous Incident Data Service, 2007. In AEA technology. London: HSE-Health and Safety Executive (United Kingdom).

NTSB, U.S. National Transportation Safety Board, 1982. Pacific Gas \& Electric Company Natural Gas Pipeline Puncture, San Francisco, California, August 25, 1981, Pipeline Accident Report NTSB/PAR-82/01, Washington, DC.

NTSB, U.S. National Transportation Safety Board, 2012. Hazardous Liquid Pipeline Rupture and Release, Marshall, Michigan, July 25, 2010, Pipeline Accident Report NTSB/PAR-12/01, Washington, DC.

NTSB, U.S. National Transportation Safety Board, 2014. Pipeline Accident Reports. www.ntsb.gov/ (Accessed: November 6, 2014.).

Papadakis, G.A., 1999. Major hazard pipelines: a comparative study of onshore transmission accidents. J. Loss Prev Process Ind., 12, 91-107. 
Ramírez-Camacho, G., Pastor, E., Casal, J., Amaya-Gómez, R., Muñoz-Giraldo, F., 2015. Analysis of domino effect in pipelines. J. Hazard. Mater., 298, 210-220.

TRB, Transportation Research Board, 2004. Transmission pipelines and land use. A risk-informed approach. Special report 281. Washington, D.C.

Trépanier, M., Marie-Hélène., L., de Marcellis-Warin. N., 2007. Cross-analysis of hazmat road accidents using multiple databases. Interuniversity Research Centre on Enterprise Networks, Logistics and Transportation. Canada.

Trépanier, M., Marie-Hélène., L., de Marcellis-Warin. N., 2009. Cross-analysis of hazmat road accidents using multiple databases. Accid Anal Prev., 41 (6), 1192-1198.

TSB, Transportation Safety Board of Canada, 2014. Pipeline investigation reports. www.tsb.gc.ca (Accessed: September 24, 2014).

Vílchez, J.A., Sevilla, S., Montiel, H., Casal, J., 1995. Historical analysis of accidents in chemical plants and in the transportation of hazardous materials. J. Loss Prev Process Ind., 8 (2), 87-96. 